\title{
The Relationship Between Industry 4.0 and Lean Production: An Empirical Study on Bursa Manufacturing Industry
}

\author{
İsa DEMIRKOL iD a Abdulmalek A. AL-FUTAIH iD \\ a Bursa Technical University, Faculty of Humanities and Social Sciences, Bursa, Turkey. demirkolisa@gmail.com \\ b Bursa Technical University, Faculty of Humanities and Social Sciences, Bursa, Turkey. sostiire@gmail.com
}

\begin{tabular}{|c|c|}
\hline ARTICLE INFO & ABSTRACT \\
\hline $\begin{array}{l}\text { Industry } 4.0 \\
\text { Industry } 4.0 \text { Applications }\end{array}$ & $\begin{array}{l}\text { Purpose - This study intends to empirically determine the effect of Industry } 4.0 \text { (digital technology) on } \\
\text { the companies adopted lean manufacturing in their production system. This study also gave importance } \\
\text { to the factors that were not discussed in previous studies, such as Cause of Problems and Equipment } \\
\text { Maintenance. }\end{array}$ \\
\hline Received 24 March 2020 & $\begin{array}{l}\text { Design/methodology/approach - The universe of this study was the businesses adopting lean } \\
\text { manufacturing system in Turkish city of Bursa. In order to achieve this goal, a survey was used as a data } \\
\text { collection method. In this context, } 250 \text { questionnaires were sent to the related companies by Simple } \\
\text { Random Sampling Method and received } 169 \text { usable responses. Then, frequency, reliability, correlation, } \\
\text { and factor (ANOVA) analyses have been used to analyze the data obtained. }\end{array}$ \\
\hline Revised 29 April 2020 & Findings - According to the research results, there are 7 dimensions of the lean production system. These \\
\hline Accepted 4 May 2020 & $\begin{array}{l}\text { dimensions are called Pull System, Production Equipment, Statistical Methods, Equipment Maintenance, } \\
\text { Product Similarities, Communication with Suppliers and Cause of Problems. Also, there have been } \\
\text { differences between industry } 4.0 \text { (digital technology) usage and lean manufacturing systems. In addition, } \\
\text { the authors found that there are significant and positive relationship between factors; Pull System, }\end{array}$ \\
\hline \multirow{2}{*}{$\begin{array}{l}\text { Article Classification: } \\
\text { Research Article }\end{array}$} & $\begin{array}{l}\text { Production Equipment, Statistical Methods, Equipment Maintenance, Product Similarities, } \\
\text { Communication with Suppliers. However, there was no significant relationship between the problems } \\
\text { causes factor and Industry } 4.0 \text { (digital technology). }\end{array}$ \\
\hline & $\begin{array}{l}\text { Discussion - Considering the results obtained, the authors suggest that companies that use lean } \\
\text { manufacturing systems should adapt to changing technology early by integrating with Industry } 4.0 \text { and } \\
\text { meeting customers' changing requirements. In addition, a quantitative approach will be presented in } \\
\text { future studies, where it is believed that companies using Industry } 4.0 \text { will make an additional contribution } \\
\text { to the literature by identifying the competencies and departments changed. }\end{array}$ \\
\hline
\end{tabular}

\section{Introduction}

In today's fast competitive economy, it is very important to run efficient procedures and practices to control the cost of manufactured products and move across the realization of lean manufacturing (Chauhan and Singh, 2013). Lean Manufacturing (LM) requires improvements of the quantity and quality of outputs with less exhaustion of resources (Tortorella at al., 2019). It emphasizes the accomplishment of value-added performances and continuous reduction in the non-value-added businesses (Chauhan and Singh, 2013). Furthermore, LM endeavors to minimize and control overproduction in industries, and determine value from a consumer perspective (Fettermann and Tortorella, 2018). Thus, there must be too few production processes, when there is no immediate demand for the products or when consumers do not need the products (Lai et al., 2019).

Industry 4.0 plants are expected to be able to acquire production equipment that combines real-time data and operates independently, based on information from the remainder of the manufacturing facility, client references and supply chain (Lai et al., 2019). At the Industry 4.0 facility, demand and information management are better linked to the workshop floor directly. Consequently, orders can be managed, and decisions can be made immediately (Mahapatra and Mohanty, 2007). Industry 4.0 applications improve efficiency in lean production

\section{$\underline{\text { Suggested Citation }}$}

Demirkol, I., Al-Futaih, A.,A. (2020). The Relationship Between Industry 4.0 and Lean Product: An Empirical Study on Bursa: Manufacturing Industry, Journal of Business Research-Turk, 12 (2), 1083-1097. 
systems, which lead to a real-time integration system. Furthermore, big data, CPS and the internet of things can boost the level of data exchange and performance in the automated production (Pagliosa et al., 2019). For instance, cyber-physical system (CPS) can supply a superior chance for precise monitoring of activities inside and outside the manufacturing work floor (Kamble et al., 2019). Industry 4.0 gives individual, client-specific criteria to be added in the layout, arrangement, ordering, delineation, industry and process phases, and enable last-minute revision to be integrated (Kagermann et al., 2013).

In light of recent studies, the growing interest of lean manufacturing enterprises in industry 4.0 technologies has given researchers an incentive to investigate whether there is an interrelationship between these two approaches. In accordance with Fettermann and Tortorella (2018) study, there is a positive relationship between industry 4.0 applications and LM practices, and high-performing company in emerging economies are very likely to promote Industry 4.0 technologies. In contrast, Rosin et al. (2019), argue that Industry 4.0 technologies affect lean principles, excluding the Internet of Things and simulation, which can be good methods for enhancing performance in lean manufacturing. However, Kolberg et al. (2016) and Wagner et al. (2017) suggest industry 4.0 technologies such as Information and Communications Technology (ICT) as a solution to meet the demands of highly customized products.

Therefore, in this study, the purpose was to examine whether there is a relationship between Industry 4.0 related technologies and LM, by developing a questionnaire targeting manufacturers in Bursa, Turkey. The study consists from five main sections. In the second section, a wide review of the subject is presented. Then in the third section, the analyzes and related results are explained. In the fourth section, the results of the study are reviewed, and suggestions were given. In the last section, the references are given.

\section{Background and Basic Concepts}

\subsection{Industry 4.0}

The term of Industry 4.0 was first used in 2011 as a tender to come up with a new principle of German economic policy based on Germany's high technological strategies (Mosconi, 2015), which stands for the 4th industrial revolution, end-to-end digital formation of physical objects, integrating economy with artificial intelligence (PWC, 2016; Rozkwitalska and Slavik, 2017). As it is shown in Fig. 1, the impact of industry 4.0 shifted from a situation seen by some as mere enthusiasm and propaganda, to tangible investments. According to PWC (2016) report, there are many companies in the Middle East have reported that they are investing significant money in this area through levels of digital transformation and integration. Industry 4.0 technologies also forced traditional production companies to adopt automation systems, due to increased production costs and competition between companies. Today, industry 4.0 technologies offer large-scale improvements in the entire industrial economy (Lai et al., 2019).

Industry 4.0 has changed into reality and produced new technology concepts, such as artificial intelligence (AI), digital production, mechanisms, IoT, three-dimensional (3D) printing, biotechnology and quantum computing (Mosconi, 2015). Furthermore, industry 4.0 has left unprecedented influences in the economic and social sectors and performs progress in the entire industry on three points (Roblek et al., 2016); 1-Digitize information systems in production and management planning. 2- Automation Systems. 3- Associating manufacturing sites with Supply Chain and Automated Data sensors. 


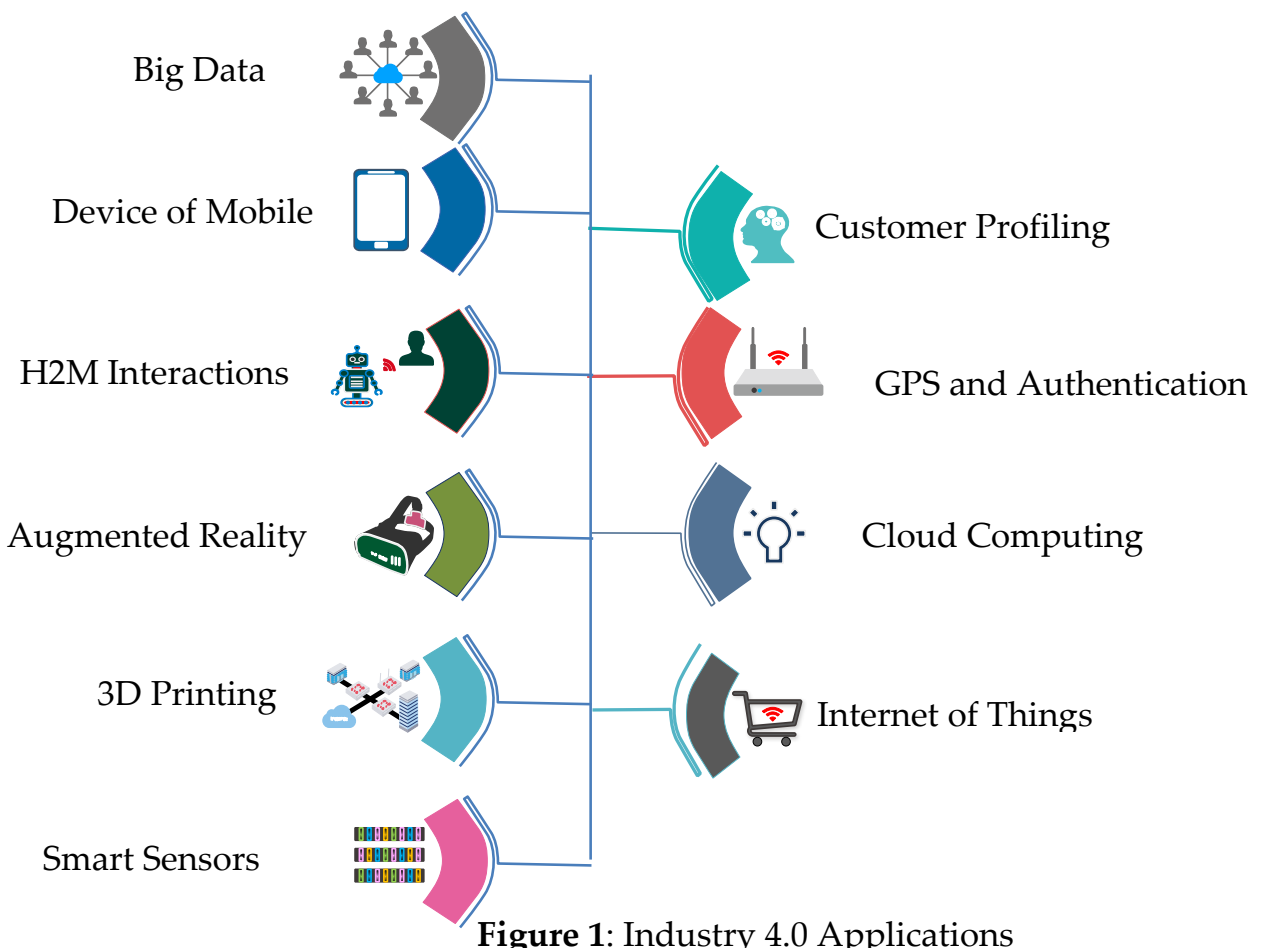

Source: prepared by authors

\subsubsection{Mobile Devices Can Be Used in Automated Production}

With mobile devices, it is possible to control production processes, such as completing checklists, getting and meeting orders, observing workstations and visualizing the right optimization in the production environment (Morkos et al., 2012). The manufacturing systems will be powered by mobile devices. This new approach will force manufacturers to think again and more efficiently. Furthermore, smart factories are taking advantage of an integrated set of new technologies to enhance productivity and increase their revenues (Gibson, 2019).

\subsubsection{Internet of Things and Machine Integration}

IoT refers to any device used to collect information from the surrounding environment and then shares them over the Internet, from which the data is processed in a smart way to provide the required information and services (Cheruvu et al., 2019). So, Internet of things provides combined services, which enable machines to make diverse operations and services without the need for human intervention (Choi et al., 2016). IoT features views of sensors, networks, devices, applications, APIs, and data, which industrial companies are looking to leverage this maturity environment to improve operational efficiency and performance in manufacturing (Accenture, 2019).

\subsubsection{H2M Interactions}

$\mathrm{H} 2 \mathrm{M}$ is a platform for the implementation of intelligent manufacturing, which concentrates primarily on procedures of interaction, intelligent communication and transactions between humans and machines (Ma et al., 2019). In the human-machine system, people receive information from the device through the visual and auditory system; then, with conversion and resolution in the brain, the motor organ interacts to achieve the transfer of information between human and machine (Deng et al, 2015).

\subsubsection{GPS provides adequate information}

GPS has a wide range of applications, including package tracking delivery, mobile device trading, emergency response, exploration, inspection, enforcements, entertainment, wildlife discovery, satellite data conversion, and 
resource control (Bajaj et al., 2015). Tracking methods generally depend on the distance and direction of the moving objects. This calculation is a method of estimating a primitive location that involves calculating the direction of the object and the distance from a particular position (Brown et al., 2007).

\subsubsection{Authentication \& fraudulence detection}

One of the miserable facts in call centers is fraudulent calls. Therefore, the need to authenticate legal customers is increasing day by day (Pindrop Report, 2017). Some technologies have been detected to handle the authentication request that includes the current user ID and user data. For instance, the new technique involves receiving an authentication request in an adaptive system which includes a previous database. This Database includes the identifier and previous user's data coming from the previous authentication (Villa et al, 2015).

\subsubsection{D Printing}

$3 \mathrm{D}$ printing is a complex process of engaging materials, which use to create and build objects from a 3D imaging dataset, using layer-by-layer manner instead of subtractive processing methodology (Han and Jia, 2016). 3D printing is also called "additive manufacturing", where a piece is an added material (Crease, 2018), which can change geometrical representation into physical objects by sequential extensions of materials (Han and Jia, 2016). It is adopted for faster and inexpensive core manufacturing processes, such as modeling, digitization, converting file data to G-code files, and printing materials using a layer-by-layer technique (Guo et al., 2019).

\subsubsection{Smart Sensors}

Compared to Industry 4.0, the improvement of sensors has seen different phases culminating in sensor 4.0. Smart sensors can be used to improve and develop manufacturing systems, thanks to their ability to monitor, diagnose and control data (Kamarthi et al., 2004). As production automation continues to expand in the industrial companies, traditional sensors are no longer suitable in manufacturing systems (Kusiak, 2018). Industrial automation has a strong demand for high-quality sensor products, especially viscosity sensor, hardness, surface finish, configuration, and color. And this has strict quality requirements (Schütze et al., 2018). Combined with factory systems and supported by accelerated intelligent sensor technology, smart technologies have a profound influence on the performance of the industrial system and ultimately lead to high quality, flexibility and productivity in manufacturing systems (LMI Technologies, 2018).

\subsubsection{Big Data Analysis in Manufacturing}

To confirm the best view of what happens in industrial infrastructure at any time, big data analysis has included the search for compact and predictable methods. However, the attributes of the data to be analyzed usually require some types of human intuition (Rehman et al., 2019). The database contains start and end dates for several weekly sales and profit promotion campaigns. Critical data may not be the same dates, but the periods between them and may not be gross profit but average profit over those periods. Big data analytics levels are machine learning, deep learning and supervised learning (Gibson, 2019).

\subsubsection{Augmented Reality/Wearables}

This technology provides a wide range of advantages in manufacturing, education, entertainment, medicine, and engineering (Silva et al., 2003). The augmented reality system consists of real scene data, scene location information and analysis, realistic scene, and the integration of display (He et al., 2017), which assigned to the digital supporting systems. AR allows digital interference with the physical world, which the user sees, unlike virtual reality, which requires wearing a special helmet and other computer-related accessories that allow the virtual world to interact with the user (Sorko and Brunnhofer, 2019).

\subsubsection{Cloud Computing enables manufacturers to have IT resources}

Cloud computing (CC) is a collection of computing that is grouped and interlocked somewhere to perform many functions that serve a large segment of users at the same time and in different places (Nwobodo, 2016), allowing businesses to sell computing resources efficiently (Puttonen et al., 2016). CC enables the manufacturing a new and 
efficient mechanism to reduce production costs through the transmission of monitoring data in manufacturing by centralized analytical servers (Wang et al., 2015), and thanks to their hardware independence, maintenance, high performance, productivity, reliability, and security (Nwobodo, 2016). It can increase the efficiency in LM that requires considerable effort, such as modeling design processes (Wang et al., 2017).

\subsection{Lean Production and 8 Waste}

Table 1: The 8 waste in lean manufacturing system

\section{Defects: \\ - Reports without complete information. \\ - Incorrect reports or data \\ - Clients' calls are not answered.}

Inventory Excess /Backlog:

- Poor balance of workloads

- Processing work is in huge batches.

- Accumulation of files that are no longer used.

\section{Transportation:}

- Lots of effort to get services.

- Too many mice click on website to get information

\section{Overproduction (Over-Processing):}

- Production exceeds consumer demand.

- Failure to design products from a customer

perspective.

- Poor understanding of what client really needs.

\section{Waiting (Long Standby Time):}

- Customers waiting for goods/services.

- Waiting for call/email response.

- Staff waiting for invoices and information

from co-workers

Non value-added processing:

- Distribution of unread information.

- Reports are too long and elaborate.

- Creating services not required.

\section{Motion Waste:}

- Excessive staff movements.

- Ineffective layouts /search for misleading elements.

\section{Underutilizing People's Abilities:}

- Not using employees' knowledge, skills, and abilities efficiently.

- Using high skills in non-value-added

\section{Source: Prepared by authors}

Lean is used as a set of management essentials and methods provided towards waste disposal in the manufacturing procedures, to increase the efficiency of production and add value to the products from the customer's perspective (Kamble et al, 2019). Lean manufacturing is a systematic way to minimize production costs by identifying 8 problems within the manufacturing system and eliminating unnecessary waste without sacrificing productive capacity (Mahapatra and Mohanty, 2007). LM is derived from Toyota's production system theory. In 1990s, Prof. D. Jones from Massachusetts Institute of Technology used the term Lean Production instead of the term "JIT" in his book "The Machine That Changed the World" (Guan et al., 2017).

Lean manufacturing is a multidimensional approach that covers a wide range of management applications such as JIT in the integrated manufacturing system, quality system, industrial cellular manufacturing (to organize the production equipment into machine), and supply chain management (SCM) (Badurdeen and Stump, 2008). As it is shown in Figure-2, LM can provide a wide range of advantages, including production efficiency, reworking overall performance, quality, and staff efficiency and their enthusiasm (Baecker, 2012). Another advantage of lean manufacturing is the capability of this system to minimize the waste in the over-processing, overproduction, transmission, inventory, and defects, as well as reducing unnecessary motions of equipment or personnel and waiting for the next production procedures and steps (Lai et al., 2019). 


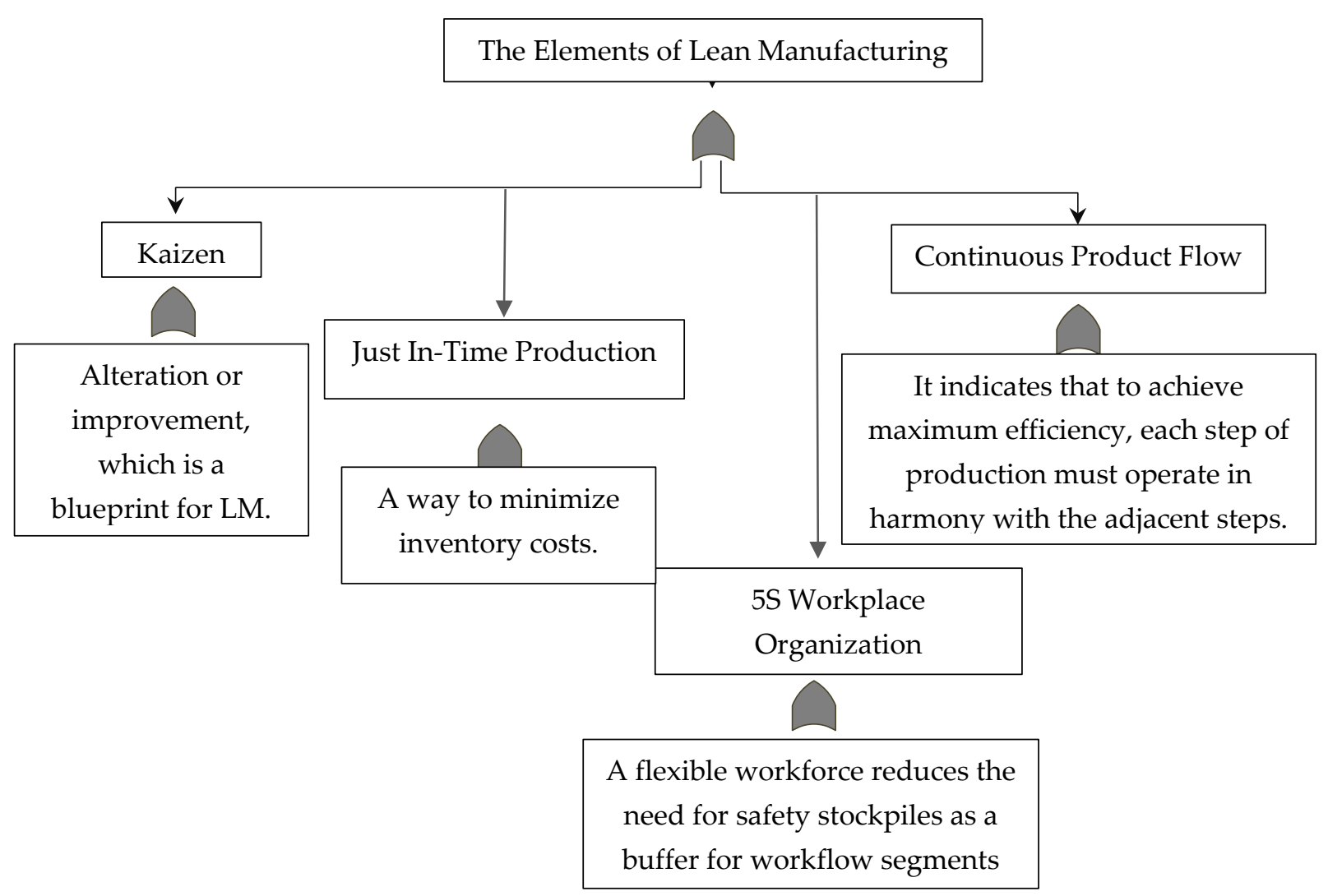

Figure 2. The Elements of Lean Manufacturing Source: Prepared by authors

\section{Method}

In this descriptive research, a questionnaire was used as a method of data collection. In order to test the validity of the metrics in the pre-test conducted in the questionnaire, the opinions of academics and some managers who are subject matter experts were taken, and a draft questionnaire was created with the necessary changes in relation to the issues they noticed. Then, a pilot study was carried out with 26 people from related fields in the units where they work, so that the questionnaire was tested before the actual application and the questions that were not understood / perceived by everyone were determined. In accordance with the opinion and suggestions from the people surveyed within the scope of the pilot study, the corrects/additions were considered necessary were made and the final version of the survey form was given.

The research questionnaire consists of 3 sections and 41 questions. In the first section, questions about the demographic characteristics were presented. In the second section, 21 questions have been developed to determine the level of implementation of lean production, taking advantages from Rossini et al. (2019) studies. As well as in third section which includes 16 questions about digital technology. Expressions about lean production and the use of digital technology on the scale are measured with the 5-lirt measurement method; "absolutely disagree", " disagree", " not sure", "agree" and "absolutely agree".

The universe of this research consists of companies that continue to operate in Turkey - Bursa province. Accordingly, the level of significance is set to $\mathrm{Z}_{0.05}=1.96$ for $\alpha=0.05$, standard deviation $\mathrm{s}=1$, and sample error $\mathrm{d}=0.1$ and the minimum sample size is calculated as 120 . Most statisticians agree that the lowest sample size to get a meaningful result is 100 (Bryman and Bell, 2003). In the study, 250 questionnaires were sent to related companies through a simple random sampling method. 169 of them were answered. After receiving the questionnaires, 4 of them were excluded, as they are not subject to analysis due to lack of information. SPSS 23 software for the Windows was used to evaluate the remaining 169 questionnaires. In this study, frequency and percentage 
distributions were used for the characteristics of companies. On the other hand, arithmetic mean and standard deviation values for the scale and subscales (sub-dimensions) were calculated. The relationships between the scale and its sub-dimensions were determined by Pearson correlation analysis. However, analysis of variance (since parametric test assumptions are provided) that measure lean manufacturing sub-factors, pull system, production equipment, statistical methods, equipment maintenance, product similarities, communication with suppliers, and causes of problem factors with Industry 4.0 technologies have been applied. On the other hand, explanatory factor analysis was applied for the construct validity of the scales and the internal consistency related to the reliability analysis was calculated with Cronbach's Alpha coefficients.

\section{Results}

\subsection{Demographic Characteristics}

Table 2. Demographic Characteristics

\begin{tabular}{|c|c|c|c|c|c|c|c|}
\hline $\begin{array}{l}\text { Demographic } \\
\text { Characteristics }\end{array}$ & & $\mathbf{n}$ & $\%$ & & & $\mathbf{n}$ & $\%$ \\
\hline \multirow{3}{*}{ Number of Employees } & $\begin{array}{l}<500 \\
\geq 500\end{array}$ & $\begin{array}{l}110 \\
59\end{array}$ & $\begin{array}{l}65,1 \\
34,9\end{array}$ & \multirow{3}{*}{ Ownership } & $\begin{array}{l}\text { Single } \\
\text { Property }\end{array}$ & 57 & 33,8 \\
\hline & \multirow{2}{*}{ Total } & \multirow{2}{*}{169} & \multirow{2}{*}{100} & & & 112 & 66,2 \\
\hline & & & & & $\begin{array}{l}\text { Multiple } \\
\text { Property }\end{array}$ & 169 & 100 \\
\hline \multirow{3}{*}{ Business Model } & B2B & 107 & 63,3 & \multirow{3}{*}{ Lean Time } & $5<$ & 81 & 47,9 \\
\hline & $\mathrm{B} 2 \mathrm{C}$ & 62 & 36,7 & & $5 \geq$ & 88 & 52,1 \\
\hline & Total & 169 & 100 & & & 169 & 100 \\
\hline
\end{tabular}

The demographic findings of the research are shown in table 2. When the distribution of employees is examined, there are 110 businesses (65.1\%) have less than 500 employees, and 59 (34.9\%) businesses have number of employees more than 500. When analyzed in terms of the model of enterprises, it is shown that 107 (63.3\%) enterprises have B2B and 62 (36.7\%) enterprises have B2C business models. When examined according to their property status, most businesses (112 (66.2\%)), have multiple properties, while $57(33.8 \%)$ are found to be single property. When examined according to lean production application times, it has been seen that enterprises that apply lean production for 5 years are $88(52.1 \%)$, and the number of businesses that have implemented lean production for less than 5 years is $81(47.9 \%)$.

\subsection{Factor Analysis}

Table 3. Factor Analysis Results

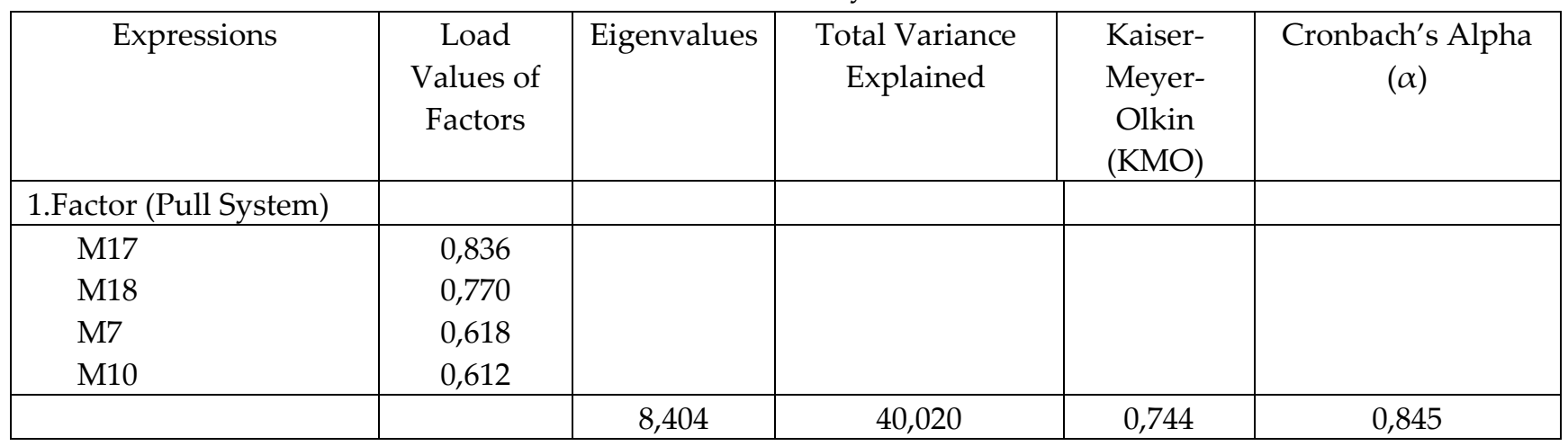


İ. Demirkol - A. A. Al-Futaih 12/2 (2020) 1083-1097

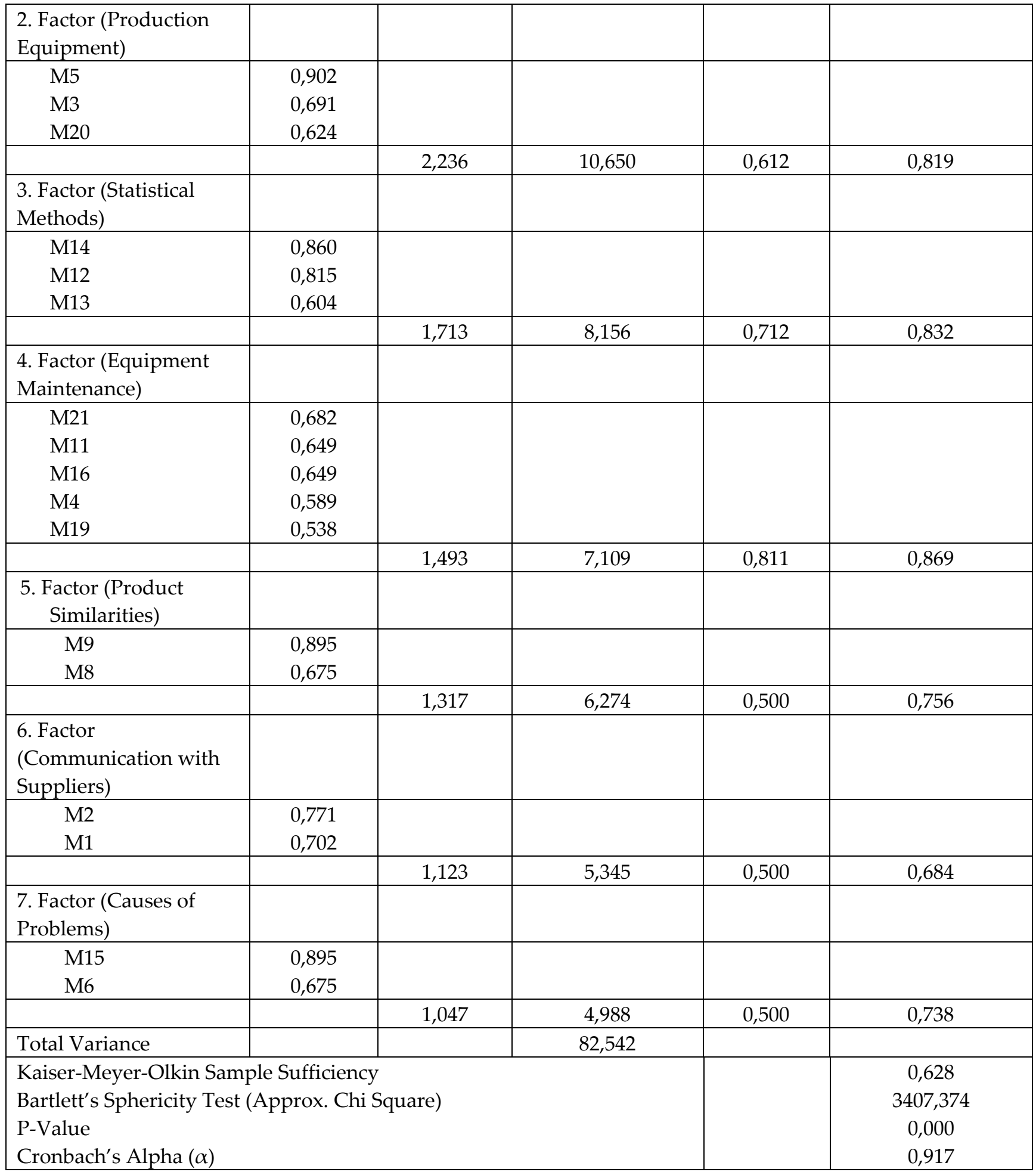

In order to demonstrate the construct validity of the scales used in the research: firstly, explanatory factor analysis was performed. In this context, the suitability of the scales for factor analysis was evaluated according to the results of Kaiser Meyer- Olkin (greater than 0.60) and Barlett's sphericity test (to be 0,000). In addition, Cronbach's Alpha coefficients were calculated to measure the reliability of the scale dimensions resulting from factor analysis. Cronbach's Alpha coefficient of the scale is 0.845, indicating that the scale is reliable. Based on the descriptive factor analysis for the Production Equipment scale, 3 expressions on the scale (M5, M3, M20) have been collected 
under a single factor with $10,650 \%$ of the total variant of these expressions (KMO $=0.612 \mathrm{p}=0.000)$. Also, the reliability coefficient of the Production Equipment Scale has been found as 0.819 .

When the explanatory factor analysis for Statistical Methods scale has been analyzed, 3 expressions (M14, M12, M13) in the scale have been gathered under a single factor and these statements express $8,156 \%$ of the total variance $(\mathrm{KMO}=0,702 \mathrm{p}=0,000)$. The reliability coefficient of the Statistical Methods Scale is 0.832 . Based on the explanatory factor analysis for the Equipment Maintenance scale, it is explained that 5 expressions (M21, M11, M16, M4, M19) have been aggregated under a single factor with 7,109\% of the total variance of these expressions $(\mathrm{KMO}=0,811 \mathrm{p}=0,000)$. The reliability coefficient of the Equipment Maintenance Scale is 0.869 . Based on the explanatory factor analysis for the scale of Product Similarities, the two expressions on the scale (M9, M8) have been collected as a single factor, describing $6,274 \%$ of the total variant of these expressions $(\mathrm{KMO}=0.500 \mathrm{p}=0.000)$. The reliability coefficient of the Product Similarities Scale is 0.756 . Based on explanatory factor analysis for the scale of Communication with Suppliers, 2 expressions (M2, M1) on scale are collected under a single factor and describe $5,345 \%$ of the total variant of these expressions $(\mathrm{KMO}=0.500 \mathrm{p}=0.000)$. It is seen that the reliability coefficient of the Communication with the Suppliers Scale is 0,684 . Finally, when looking at the explanatory factor analysis for the Causes of Problem scale, it indicates that the two expressions (M15, M6) in the scale are gathered under a single factor, and these expressions explain $4.98 \%$ of the total variance $(\mathrm{KMO}=0.500 \mathrm{p}=0.000)$. Reliability coefficient of the Problem Causes Scale is 0.738. In total, Kaiser-Meyer-Olkin Sample Sufficiency 0.628, Bartlett's Sphericity Test Approx. Chi Square 3407,374 and Cronbach's Alpha $(\alpha)$ value 0.917, and that means highly reliable.

\subsection{Difference Tests}

As shown in table 4, we have applied for Tamhane's T2 test to see the differences between groups, since variance homogeneity (Sig.0.05) could not be achieved in the results obtained to the pull system, production equipment, statistical methods, equipment maintenance, product similarities, communication with suppliers and Cause of Problems scale.

Table 4. Difference Tests

\begin{tabular}{|c|c|c|c|c|}
\hline & Levene Statistic & Df1 & Df2 & Sig. \\
\hline Pull System & 3,498 & 13 & 156 &, 000 \\
\hline Production Equipment & 2,657 & 13 & 156 &, 034 \\
\hline Statistical Methods & 1,896 & 13 & 156 &, 047 \\
\hline Equipment Maintenance & 1,801 & 13 & 156 &, 000 \\
\hline Product Similarities & 3,593 & 13 & 156 & 003 \\
\hline Communication with Suppliers & 2,564 & 13 & 156 &, 000 \\
\hline Problem Causes & 3,753 & 13 & 156 & \\
\hline
\end{tabular}

\subsection{ANOVA Analysis}

One of the limitations of ANOVA analysis is that it indicates whether the means of the data are different from each other. Moreover, the ANOVA analysis diffuses the variance between the various patterns tested (Buckless and Ravenscroft, 1990). 
Table 4. ANOVA Analysis

\begin{tabular}{|c|c|c|c|c|c|c|}
\hline & & Sum of Squares & $\mathrm{df}$ & Mean Square & $F$ & Sig. \\
\hline \multirow[t]{3}{*}{$\mathrm{F} 1$} & Between Groups & 19,712 & 13 & 1,516 & 3,873 & ,000 \\
\hline & Within Groups & 61,076 & 156 & ,392 & & \\
\hline & Total & 80,788 & 169 & & & \\
\hline \multirow[t]{3}{*}{$\mathrm{F} 2$} & Between Groups & 19,785 & 13 & 1,522 & 2,939 & ,001 \\
\hline & Within Groups & 80,782 & 156 &, 518 & & \\
\hline & Total & 100,567 & 169 & & & \\
\hline \multirow[t]{3}{*}{ F3 } & Between Groups & 11,585 & 13 & ,891 & 2,079 & ,018 \\
\hline & Within Groups & 66,856 & 156 & ,429 & & \\
\hline & Total & 78,440 & 169 & & & \\
\hline \multirow[t]{3}{*}{$\mathrm{F} 4$} & Between Groups & 43,434 & 13 & 3,341 & 6,346 & ,000 \\
\hline & Within Groups & 82,132 & 156 &, 526 & & \\
\hline & Total & 125,566 & 169 & & & \\
\hline \multirow[t]{3}{*}{ F5 } & Between Groups & 35,809 & 13 & 2,755 & 5,935 & ,000 \\
\hline & Within Groups & 72,402 & 156 & ,464 & & \\
\hline & Total & 108,212 & 169 & & & \\
\hline \multirow[t]{3}{*}{ F6 } & Between Groups & 25,887 & 13 & 1,991 & 3,312 & ,000 \\
\hline & Within Groups & 93,789 & 156 & 601 & & \\
\hline & Total & 119,676 & 169 & & & \\
\hline \multirow[t]{3}{*}{ F7 } & Between Groups & 54,402 & 13 & 4,185 & 5,903 & ,000 \\
\hline & Within Groups & 110,600 & 156 & 709 & & \\
\hline & Total & 165,001 & 169 & & & \\
\hline
\end{tabular}

ANOVA analysis is given in table 5 it has been tested whether there is a difference between the hypotheses created based on different independent variables. If the Sig. value given in the ANOVA table is less than 0.05, it indicates that there is a difference between the groups. We can create the following hypothesis:

H1: There will be a significant difference between Digital Technology and Pull System.

In the independent sample $\mathrm{t}$ test $(\mathrm{F}=3,873 ; \mathrm{p}=0,000<0.05)$, the $\mathrm{H} 1$ hypothesis was accepted and there is a significant difference between the use of digital technologies and the pull system.

H2: There will be a significant difference between Digital Technology and Production Equipment.

In the independent sample $\mathrm{t}$ test $(\mathrm{F}=2.939 ; \mathrm{p}=0.000<0.05)$, the $\mathrm{H} 2$ hypothesis was accepted, which means that there is a significant difference between the use of digital technologies and the use of production equipment.

H3: There will be a significant difference between Digital Technology and Statistical Methods.

In the independent sample $\mathrm{t}$ test $(\mathrm{F}=2.079 ; \mathrm{p}=0.000<0.05)$, the $\mathrm{H} 3$ hypothesis was accepted, giving that there is a significant difference between the use of digital technologies and the use of Statistical methods.

H4: There will a significant difference between Digital Technology and Equipment Maintenance. 
In the independent sample $\mathrm{t}$ test $(\mathrm{F}=6,346 ; \mathrm{p}=0,000<0.05)$, the $\mathrm{H} 4$ hypothesis was accepted. So, there is a significant difference between the use of digital technologies and Equipment maintenance methods.

H5: There will be a significant difference between Digital Technology and Product Similarities.

In the independent sample $t$ test $(F=5,935 ; p=0,000<0.05)$ H5 hypothesis was accepted; there is a significant difference between the use of digital technologies and product similarities.

H6: There will be significant difference between Digital Technology and Communication with Suppliers.

In the independent sample $t$ test $(F=3,312 ; p=0,000<0.05)$, the $\mathrm{H} 6$ hypothesis was accepted and there is a significant difference between the use of digital technologies and the processes of communication with the Suppliers.

H7: There will be a significant difference between Digital Technology and determination of the causes of the Problem.

In the independent sample $t$ test $(F=5,903 ; p=0,000<0.05)$, the H7 hypothesis was accepted and shows a significant difference between the use of digital technologies and determining the causes of problems.

\subsection{Correlation Tests}

Table 6. The Relationship Between Digital Technology and Factors

\begin{tabular}{|c|c|c|c|c|c|c|c|c|c|}
\hline & & 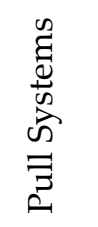 & 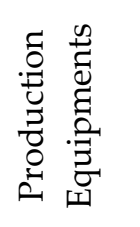 & 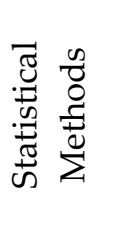 & 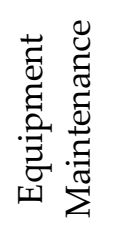 & 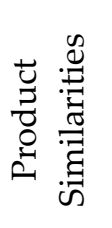 & 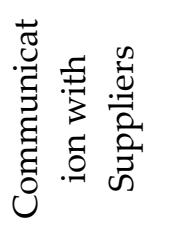 & 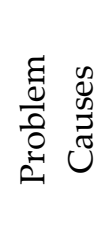 & \\
\hline \multirow{3}{*}{ 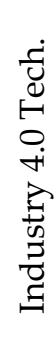 } & 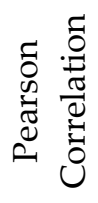 & 0,133 & 0,078 & 0,160 & 0,276 & 0,337 & 0,196 & & 0,061 \\
\hline & $\mathrm{p}$ & 0,034 & 0,010 & 0,003 & 0,000 & 0,000 & 0,000 & & 0,431 \\
\hline & $\mathrm{N}$ & 169 & 169 & 169 & 169 & 169 & 169 & & 169 \\
\hline
\end{tabular}

Also, when we look at the relationship between the use of digital technology and lean production factors, it is seen that there is a positive and significant relationship with the pull system, production equipment, statistical methods, equipment maintenance, product similarities, communication factors with the suppliers. However, it is seen that there is no significant relationship between the cause of problems factor and digital technology (Industry 4.0).

\section{Conclusion and Discussion}

It is a well-known fact that the presence of companies in the developing and changing world depends on their continuity, competitiveness and sustainability. Although there are many effective environmental factors that ensure the competitive advantage of these companies, the added value thanks to the lean manufacturing system and industry 4.0 remains the most relevant factor in the continuity and competitiveness today.

The purpose of of this paper is to identify and measure the relationship and differences between industry 4.0 and lean manufacturing system. Accordingly, the hypotheses have been created and the theoretical framework have been tested. The following findings have been reached to measure the relationships and differences between the variables. 
The majority of enterprises have been using lean production system for more than 5 years. In addition, they have Multi-ownership, and run a B2B business model. Each company has fewer than 500 employees. Looking at results, it has been determined that there are significant differences between industry 4.0 and all variables such as pull system, lean manufacturing factors, production equipment, statistical methods, equipment maintenance, product similarities, communication with suppliers and determining the causes of problems. Then, in correlation analysis, it was determined that there is a significant and positive relationship between industry 4.0 and pull system, production equipment, statistical methods, equipment maintenance, product similarities, and communication with suppliers. However, it has been determined that there is no significant relationship between determining the causes of problems and Industry 4.0. The reason for this can be said that there are uncertainties in the quality problems that make up the factor. In this regard, companies that use lean manufacturing systems should adapt to changing technology by integrating with Industry 4.0 technologies that will enable them to quickly meet customers' changing requirements earlier. In this respect, the research shows a similarity with (Rossini et al., 2019) study, which examines the relationship between LM and industry 4.0 applications. However, the relationship between the causes of problem, which is the 7th factor, and industry 4.0, differs from the results section of the (Rossini et al., 2019) research. In the results of factor analysis, the causes of problem have similar results to a study of (Kafuku, 2019), which also overlaps with the results. There are also similarities between the results of this study and the results of many previous studies on this topic, such as (De Oliveira et al., 2019; Tortorella et al., 2015). In the current study, a quantitative approach has been demonstrated, and the scale between lean manufacturing and industry 4.0 developed by (Rossini et al., 2019) has been tested. In future studies, the focus will be on introducing a quantitative approach, and the efficiency of firms using industry 4.0 will be determined on these limits. Emphasis will also be placed on departments affected by Industry 4.0, in order to be able to make various contributions to the literature.

\section{References}

Accenture (2019), "Internet Of Things": Https:/Www.Accenture.Com/Tr-En/Service-Mobility-Internet-Of-Things (07.11.2019).

Badurdeen, F., \& Stump, B. (2008), "Integrating Lean and Other Strategies for Mass Customization manufacturing: A Case Study", University of Kentucky, 23:109-124.

Baecker, M. (2012), "Improving Lean Manufacturing with Digital Technologies", Tecnomatix, Emea Marketing, Siemens Plm Software, 12-13.

Bajaj, R., Agrawal, D., \& Ranaweera, S. (2015), “Gps: Location tracking Technology, Computer”, 35(4):92 - 94: Https://Www.Researchgate.Net/Publication/2955618_Gps_Location-Tracking_Technology (02.11.2019).

Brown, T., Mccabe, S., \& Wellford, C. (2007)," Global Positioning System (Gps) Technology for Community Supervision: Lessons Learned", National Criminal Justice Reference Service, 1-150.

Bryman, A. \& Bell, E. 2003. Business Research Methods, Oxford, Oxford University Press.

Buckless, F. A. \& Ravenscroft, S. P. (1990). "Contrast Coding: A Refinement of ANOVA in Behavioral Analysis", The Accounting Review, American Accounting Association, 65, No. 4, pp. 933-945.

Chauhan, G., \& Singh, T. (2013), “Significant Parameters of Labour Flexibility Contributing to Lean Manufacturing", Global Journal of Flexible Systems Management, 14(2):93-105.

Cheruvu, S., Kumar, A., Smith, N., \& Wheeler, D.M. (2019), Demystifying Internet of Things Security, Open Access.

Choi, H., Lim, S., \& Kim, J. (2016), “An Efficient Expression Technique for Promotional Video Production Based On Iot (The Internet of Things) In Cultural Art Institutions, Available On Springer Link: Multimed Tools App, 75:14111-14124.

Crease A. (2018), "What Is 3d Printing? Mark forged Manufacturer Of Industrial 3d Printers": Https://Markforged.Com/Learn/What-Is-3d-Printing/?Mfa=Sga-Em-Tof- 
İ. Demirkol - A. A. Al-Futaih 12/2 (2020) 1083-1097

3dprinteraud\&Adg=73046185330\&Kw=3d\%20printer\&Device=C\&Gclid=Cj0kcqia-

4nubrcnarisahwyupqmxdpc6ibee6aqh85g1sp_V_Yghvd80orvyzoewm7zghvlb6gdmn4aakqgealw_Wcb (06.11.2019).

De Oliveira, R.I., Sousa, S.O., \& de Campos, F.C. Lean manufacturing implementation: Bibliometric analysis 20072018. Int. J. Adv. Manuf. Technol. 2019, 101, 979-988.

Deng, L., Wang, G., \& Yu, S. (2015), Layout Design of Human-Machine Interaction Interface Of cabin Based On Cognitive Ergonomics and Ga-Aca, Computational Intelligence and Neuroscience: 1-12.

Fettermann, D., \& Tortorella, G.L. (2018), “Implementation of Industry 4.0 And Lean Production in Brazilian Manufacturing Companies", International Journal of Production Research, 56(8): Pp. 2975-2987.

Gibson, J. (2019), The Future Of Manufacturing Will Be Powered By Mobile: Https://Insights.Samsung.Com/2019/10/01/The-Future-Of-Manufacturing-Will-Be-Powered-By-Mobile2/(02.11.2019).

Guan,T.; Sun, L., \& Tong, X.,( 2017), Discussion On The Optimization Of Assembly Process For Urban Rail Vehicle Based On The Lean Intelligent Manufacturing Model, School Of Mechanical Engineering, Dalian Jiaotong University, 1081- 1084.

Guo, H., Lv, R. Bai, S. (2019), Recent Advances On 3d Printing Graphene-Based Composites, Nano Materials Science 1: 101-115.

Han, Y., \& Jia G. (2016), Optimizing Product Manufacturability in 3d Printing, Frontiers of Computer Science, 11(2): 347-357.

He, Z., Chang, T., Lu, S., Ai, H., Wang, D., \& Zhou, Q. (2017), Research On Human-Computer Interaction Technology of Wearable Devices Such as Augmented Reality Supporting Grid Work, Procedia Computer Science, 107: Pp. $170-175$.

Kafuku, M. J., (2019), Factors for Effective Implementation of Lean Manufacturing Practice in Selected Industries in Tanzania, Procedia Manufacturing Volume 33, Pages 351-358

Kagermann, H., J. Helbig, A. Hellinger, W. Wahlster (2013), Recommendations for implementing the strategic initiative INDUSTRIE 4.0, Forschungsunion, Frankfurt/Main.

Kamarthi, S., Gupta, S., \& Srikanth, V. (2004), Modeling Smart Sensor Integrated Manufacturing Systems, Northeastern University, The International Society for Optical Engineering: Pp. 30-37.

Kamble, Sachin, Angappa Gunasekaran, and Neelkanth C. Dhone. (2019). "Industry 4.0 and Lean Manufacturing Practices for Sustainable Organisational Performance in Indian Manufacturing Companies." International Journal of Production Research: 1-19. doi:10.1080/00207543.2019.1630772

Kolberg, D., Knobloch, J., \& Zühlke, D. (2016), Towards A Lean Automation Interface for Workstations, International Journal of Production Research, Forthcoming, 55: 2845-2456.

Kusiak, A. (2018), Fundamentals of Smart Manufacturing: A Multi-Thread Perspective, Annual Reviews in Control (47): 214-220.

Lai, N. Y. G., Wong, K. H., Halim, D., Lu, J., \& Kang, H. S. (2019), Industry 4.0 Enhanced Lean Manufacturing, 2019 8th International Conference On Industrial Technology and Management: Pp. 206-211.

Lmi Technologies (2018), Trends In 3d Inspection: Edge Computing, Acceleration, And 3d Smart Sensors For Iiot: Https://Lmi3d.Com/Edge-Computing-Acceleration-And-3d-Smart-Sensors-Iiot (06.11.2019).

Ma, X., Tao, F., Zhang, M., Wang,T., \& Zuo, Y. (2019), Digital Twin Enhanced Human-Machine Interaction In Product Lifecycle,Procedia Cirp 83: 789-793. 
Mahapatra S. S. \& Mohanty S. R. (2007), Lean Manufacturing in Continuous Process Industry; An Empirical Study, Journal of Scientific And Engineering Research, 19-27.

Morkos, B., Taiber,J., Summers,J., Mears,L., Fadel,G., \& Rilka, T. (2012), Mobile Devices Within Manufacturing Environments:A Bmw Applicability Study, Int J Interact Des Manuf ., 6:101-111.

Mosconi, F. (2015). The New European Industrial Policy: Global Competitiveness and The Manufacturing Renaissance. London, England: Routledge.

Nwobodo, I. (2016), Cloud Computing: Models, Services, Utility, Advantages, Security Issues, And Prototype, Computing and Engineering, School of Architecture, University of East London, Uk, Pp. 1207-1222.

Pagliosa, M., Tortorella, G., \& Ferreira, J. C. E. (2019), Industry 4.0 And Lean Manufacturing A Systematic Literature Review And Future Research Directions, Journal Of Manufacturing Technology Management.

Pindrop Report (2017), 2017 Call Center Fraud Report: Https:/Www.Pindrop.Com/WpContent/Uploads/2017/04/Fraud-Report-Global-4-24-17-Final.Pdf (06.11.2019).

Puttonen J, Lobov A, Soto MAC, Lastra JLM. (2016), Cloud computing as a facilitator for web service composition in factory automation. J Intell Manuf. 2016; 1- 14

PWC: Industry 4.0: Building the digital enterprise", 2016 Global Industry 4.0 Survey.

Rehman, M., Yaqoob, I., Saleh, K., Imran, M. Jayaraman, P., \& Perera, C. (2019), The Role of Big Data Analytics in Industrial Internet of Things, Future Generation Computer Systems, 99: Pp. 247-259.

Roblek, V., Mesko, M., \& Krapez, A. (2016), A Complex View of Industry 4.0, Sage Open, 1-11.

Rosin, F., Forget, P., Lamouri, S., \& Pellerin, R. (2019), Impacts of Industry 4.0 Technologies On Lean Principles, International Journal of Production Research, Pp. 1-18.

Rossini, M., Costa, F., Tortorella, \& Staudacher, A. (2019), The Interrelation Between Industry 4.0 And Lean Production: An Empirical Study On European Manufacturers, The International Journal of Advanced Manufacturing Technology, 102:3963-3976.

Rozkwitalska, M., \& Slavik, J. (2017), Around Learning and Industry 4.0 In Management Theory, International Journal of Contemporary Management Volume, 16(4): Pp. 185-206.

Schütze, A., Helwig, N., \& Schneider, T. (2018), Sensors 4.0 - Smart Sensors and Measurement Technology Enable Industry 4.0.

Silva, R., Oliveira, J., \& Giraldi, G. (2003), "Introduction to Augmented Reality”, National Laboratory for Scientific Computation, Pp. 1-10.

Sorko, S., \& Brunnhofer, M. (2019), Potentials of Augmented Reality in Training, Procedia Manufacturing, 31: Pp. $85-90$.

Tortorella, G., G. Marodin, R. Miorando, and A. Seidel. 2015. “The Impact of Contextual Variables on Learning Organization in Firms That Are Implementing Lean: A Study in Southern Brazil." The International Journal of Advanced Manufacturing Technology 78 (9-12): 1879-1892.

Tortorella,G., Giglio, R., \& Dun, D. (2019), Industry 4.0 Adoption as A Moderator Of The impact Of Lean Production practices On Operational performance Improvement, International Journal Of OperationsE Production Management.

Villa Y., Kaufman A., Marcelo B. (2015), Fraud Detection In Adaptive Authentication Systems, U.S. Patent : Https://Patentimages.Storage.Googleapis.Com/A8/33/32/Bd2bf9039b39f4/Us8973096.Pdf (02.11.2019).

Wagner, T., Herrmann, C., \& Thiede, S. (2017), Industry 4.0 Impacts On Lean Production Systems, Procedia CIRP, 63: $125-131$. 
İ. Demirkol - A. A. Al-Futaih 12/2 (2020) 1083-1097

Wang, P., Gao, R., \& Fan Z. (2015), "Cloud Computing for Cloud Manufacturing: Benefits and Limitations", Journal of Manufacturing Science and Engineering, 137: Pp. 1-9.

Wang, Y., Li, J., \& Wang, H. H. (2017), Cluster and Cloud Computing Framework for Scientific Metrology in Flow Control, Cluster Comput, 22: S1189-S1198. 